\title{
A Pre-service Pathway for Preparing Future AP CS Principles Teachers
}

\author{
Jeff Gray \\ Department of Computer Science \\ University of Alabama \\ Tuscaloosa, AL USA \\ gray@cs.ua.edu
}

\author{
Karl Hamner \\ Office of Evaluation \\ College of Education \\ University of Alabama \\ Tuscaloosa, AL USA \\ khamner@ua.edu
}

\author{
Rebecca Odom-Bartel \\ Department of Computer Science \\ University of Alabama \\ Tuscaloosa, AL USA \\ rlodombartel@cs.ua.edu
}

\author{
Jeremy Zelkowski \\ Secondary Mathematics Education \\ University of Alabama \\ Tuscaloosa, AL USA \\ jzelkowski@ua.edu
}

\begin{abstract}
The surge of interest in K-12 computer science (CS) over the past decade has led to a deep need for a corresponding expansion of trained teachers. The primary focus of most K-12 CS teacher professional development has been for current in-service teachers who have little background in CS. To raise the importance of CS within Colleges of Education, we believe that new pathways and experiences are needed for pre-service Education majors to learn more about authentic CS topics and pedagogy. This experience report summarizes our efforts over the past two years to prepare Secondary Math Education (SEMA) majors to teach AP CS Principles (AP CSP). Our approach consists of the following curricular activities: 1) a two-course sequence, with the first course mapping to the content topics of the AP CSP Curriculum Framework, and the second course consisting of a reflection of CS methods and pedagogy, including opportunities for SEMA students to develop and present their own AP CSP lesson plans; 2) opportunities for SEMA students to observe AP CSP classrooms in local high schools through our partnership with experienced AP CSP teachers; 3) summer participation in a College Board AP Summer Institute for AP CSP, and 4) a six-week ETS Praxis CS preparation modules-based course, offered to both pre-service SEMA students and in-service teachers. We summarize our lessons learned and present results that suggest our approach is preparing pre-service students with pedagogical and content knowledge that meets or exceeds current in-service training models (including an analysis of recent Praxis results for CS certification in our state).
\end{abstract}

Permission to make digital or hard copies of all or part of this work for personal or classroom use is granted without fee provided that copies are not made or distributed for profit or commercial advantage and that copies bear this notice and the full citation on the first page. Copyrights for components of this work owned by others than ACM must be honored. Abstracting with credit is permitted. To copy otherwise, or republish, to post on servers or to redistribute to lists, requires prior specific permission and/or a fee. Request permissions from Permission@acm.org. SIGCSE'20, March 11-14, 2020, Portland, OR, USA

(C) 2020 Association for Computing Machinery

ACM ISBN 978-1-4503-6793-6/20/03...\$15.00

https://doi.org/10.1145/3328778.3366945

\author{
Sierra Rodgers-Farris \\ Office of Evaluation \\ College of Education \\ University of Alabama \\ Tuscaloosa, AL USA \\ serodgers@ua.edu
}

\section{CCS CONCEPTS}

Social and professional topics $\rightarrow$ Professional topics $\rightarrow$ Computing education $\rightarrow \mathrm{K}-12$ education; Social and professional topics $\rightarrow$ Professional topics $\rightarrow$ Computing education $\rightarrow$ Model curricula

\section{KEYWORDS}

AP Computer Science Principles, Pre-service Education, Teacher Certification

\section{ACM Reference format:}

Jeff Gray, Rebecca Odom-Bartel, Jeremy Zelkowski, Karl Hamner and Sierra Rodgers-Farris. 2020. A Pre-service Pathway for Preparing Future AP CS Principles Teachers. In Proceedings of ACM Technical Symposium on Computer Science Education (SIGCSE'20). ACM, Portland, OR, USA, 6 pages https://doi.org/10.1145/3328778.3366945

\section{Introduction}

Computer science (CS) occupations continue to be in highdemand, as evidenced by an August 2019 CareerBuilder survey that observed "software developer" as the top occupation in 20 states across the USA [1]. To raise awareness about CS opportunities, Jan Cuny of the National Science Foundation (NSF) initiated a call to action [2] for training over 10k K-12 CS educators in the USA. Over the past decade, this has led to a deep interest in new CS curricula options and professional development (PD) training workshops across all grade levels. The core challenge in scaling K-12 CS education is the reality that most existing in-service teachers (i.e., those who are already in the classroom, most likely teaching a subject other than CS) do not have CS content knowledge and lack experiences with pedagogical methods for introducing CS concepts. The majority of existing K-12 educators received their teacher preparation from Colleges of Education that did not provide any formal coursework in CS $[3,4,5]$. 
Through efforts like the Code.org Advocacy Coalition [6] and the NSF-sponsored project Expanding Computing Education Pathways (ECEP) [7], an increased emphasis is being placed on Colleges of Education to include pathways that prepare preservice Education students (i.e., those who are still in college pursuing an Education degree) to teach authentic CS courses (i.e., courses focused on rigorous computational concepts, not digital literacy). In fact, one of the core Code.org Policies to make CS a foundational K-12 skill is, "Create programs at institutions of higher education to offer computer science to preservice teachers." [8] As a result, several new legislative efforts in multiple states require State Departments of Education to collaborate with Colleges of Education to design new pathways for CS teacher preparation.

In this experience report, we document our multi-year effort of collaboration between faculty from Computer Science (College of Engineering) and Secondary Mathematics Education (SEMA, in the College of Education) to define a two-course pathway with multiple activities that prepares SEMA students to teach the AP CS Principles (AP CSP) course at their future school after graduation [11]. We focus on AP CSP because of the following reasons: 1) AP CSP is the course that has experienced the largest growth and interest by schools in our state, compared to AP CSA (a programming-focused course in Java); 2) the AP CSP course has deeper appeal and potential for inclusion and diversity across a broader range of communities with varying demographics; 3) we believe that AP CSP PD is more approachable for new educators compared to AP CSA; 4) we are able to align mathematics concepts with AP CSP essential knowledge statements, which provides SEMA students with an anchor to their core mathematics education focus, 5) AP CSP can substitute as a $4^{\text {th }}$ math credit for high school graduation in Alabama, and 6) in 2011, as a College Board AP CSP Pilot, we developed a college-equivalent course that adheres to the AP CSP Curriculum Framework and fits within our teacher preparation goals (in the 2012-2013 academic year, our course was one of only two university-focused College Board CSP Pilots).

Our paper is organized as follows: In the next section, we introduce the core components that constitute the formal courses and complementary activities to prepare SEMA students to teach AP CSP. Section 3 summarizes evaluation instruments and student feedback from two cohorts of SEMA students. We present one of the successful indicators of our project in Section 4 within the context of teacher certification and the ETS Computer Science Praxis among our most recent SEMA cohort. In Section 5, we also share several lessons that we learned before our concluding remarks that offer ideas for future work.

\section{Pre-service Pathway Curricular Activities}

The core of our pre-service CS preparation consists of two courses, student observations of AP CSP classrooms, and a series of activities designed to inculcate an interest in K-12 CS education culture. This section describes each of these curricular activities.

\subsection{Content-Focused AP CSP Model Course}

SEMA students' course of study requires the completion of an introductory CS course as part of their mathematics major. In the past, that requirement was fulfilled by forcing the SEMA students to take the CS 1 course at our university (the first course for CS majors), which was not at the proper introductory level to address the needs of SEMA students. It was clear that a new option was required. At that time, our CS department was also offering a new course called CS Principles (CS 104), which was aligned to the current College Board's AP CSP Curriculum Framework (note: at the time of initial SEMA collaboration with CS 104, CS Principles was not yet an official AP course).

In CS 104, students are introduced to foundations of computing and computational thinking through exploration of the 7 Big Ideas of AP CSP (i.e., Creativity, Abstraction, Data and Information, Algorithms, Programming, the Internet, Global Impacts of Computing). In the CS 104 course, students explore the idea of CS education as a viable career path alongside their mathematics teaching. Several methods to learning and designing basic computer algorithms (e.g., CS unplugged activities are integrated into most of the lectures) anchor the course as students explore the global impacts of CS. Throughout the course, SEMA students complete many of the same projects that high school students consider throughout an AP CSP course. The CS 104 course requires four programming assignments that lead up to a final project that resembles the Create Performance Task in AP CSP. Additional CS 104 assignments include a writing assignment about the global impacts of computing, and a group assignment that explores concepts of data mining and visualization. Chapters from Blown to Bits [12] represent the key reading assignments over the semester.

We taught the CS 104 course each semester to an average of 25 students, with a majority of the students from the SEMA program. In Spring 2020, we are expanding the course to admit up to 100 students each semester by designating the course as a core for the "Computing" General Education requirement at our university. High school students who achieve a qualifying score of 3 or above on the AP CSP exam receive course credit for CS 104 at our university.

\subsection{CS Methods and Pedagogy Course}

After several years of offering CS 104 to SEMA students, we realized that there might be potential for further developing SEMA student preparation for CS education. Students who choose to continue their development as a CS educator may register for a second course (called CS 492) in the SEMA AP CSP pathway. CS 492 looks further into CS education topics and provides the "why and how" context for the AP CSP curriculum. CS 492 exposes students to multiple College Board endorsed curricula and gives students a detailed overview of continued education requirements to become a CS educator. Additionally, CS 492 students are expected to interact and observe veteran CS teachers in the local community, create their own lesson plans, experience the AP CSP Exam as would their future students, and 
commit to additional educational activities before graduation. During our first two cohorts of SEMA students to go through this pathway, we had 11 students complete CS 492 in Cohort 1 (Spring 2018) and 10 students complete CS 492 in Cohort 2 (Spring 2019), which represents over two-thirds of the total SEMA program.

\subsection{Additional SEMA Summer Experiences}

A new Alabama law (discussed in Section 4 later) provides CS certification opportunities to teachers possessing or finishing a teaching license who may now add a CS license through the Praxis exam. We added a Summer Praxis Prep course in the second year of the pathway curriculum to include a supplemental resource for SEMA students who would like to continue and become certified CS teachers in Alabama. This Summer Prep course required approximately 33 hours of PD, delivered in an online setting over the 6 weeks. SEMA students participated with veteran in-service CS education teachers and advised by several higher education faculty members as they worked through the training sequence. Bi-weekly video conferences were set up to build momentum and keep motivation high. More details about the ETS Praxis Prep course is available in Section 4.

The first two cohorts experienced the same two-course CS sequence with different options for each summer. Cohort 1 participants, who elected to continue, participated in the APSI as an additional PD to help grow their experience, exposure, and development as a CS Educator. Cohort 2 participants, who elected to continue, participated in the summer online Praxis test readiness course. We elaborate later on the lessons learned from both cohorts and provide an argument as to why we believe our pre-service pathway offers advantages over current in-service PD models (Section 5).

\section{Discussion of Student Feedback Assessment}

We used a sequential exploratory mixed methods design for formative and summative evaluation of SEMA student efforts. We explored current teaching strategies and improved upon the knowledge for preparing SEMA students in CS. The sequential mixed methods design provided valuable insight both qualitatively and quantitatively as the project moved beyond the beginning stages. We constructed an initial anonymous online survey to obtain background information and input from the students taking CS 492 regarding their preparation for and expectations from the course. We used feedback from this survey to inform focus group questions for eliciting detailed feedback from the students and make initial adjustments to the course. Focus groups met before the course and provided formative data to improve course delivery. We also met with student focus groups at the midpoint of the course to see how students felt CS 492 was progressing and how to improve the course. Finally, a focus group at the end of the course offered additional feedback to improve the next iteration of the course and to explore students' perceptions of how their participation impacted their CS content knowledge and pedagogy.
Qualitative feedback from the SEMA students in both cohorts showed that the course met or exceeded their expectations. In both cohorts, students wished for more practical teaching and class management lessons. After the course, students reported that they still planned to become math teachers. All students said that they will incorporate CS into their math lessons and many of the students reported they plan to teach CS courses at their future school. The students mostly stated that they saw themselves as using the skills from the class for creating lesson plans that incorporate CS, as well as improving their creative thinking abilities, specifically helping them to be better at problem solving, assimilating data, understanding how computing impacts society, and explaining the difference between solvable and unsolvable problems. Students from both cohorts universally agreed that CS 492 has increased their marketability. As an example, a highlighted outcome is a student who indicated that she was offered her dream job because of her new ability to teach an AP CSP course (which she is now doing for a second year).

All students completed the nationally validated Technological Pedagogical and Content Knowledge (TPACK) instrument for Secondary Mathematics pre-service teachers at the beginning and end of the course. Pre-Post change in the scores of the four measured constructs - Technology Knowledge (TK), math Content Knowledge (CK), general Pedagogical Knowledge (PK), and Technological Pedagogical Content Knowledge (TPACK) - was analyzed with a one-way ANOVA using the research derived coefficients on each of the survey items. Across both cohorts, all four constructs showed positive descriptive mean increases and the TK measure was statistically significant at the $\mathrm{p}<0.05$ level. We attribute the TK construct increase directly to CS 492 since the finding is consistent with other SEMA projects and CS 492 students did not have other technology-focused courses during the semester.

\section{Teacher Certification Opportunities}

Over the past six months, Alabama legislators passed a comprehensive new bill that provides multiple measures to support K-12 CS education, including the mandate that every high school must offer a CS course in 2020-2021. Another aspect of the legislation focuses on four options for CS teacher certification that include the following:

1. A formal CS certification for those who obtain a degree in CS, in addition to certification in another approved area (an option that few will follow due to the salary differences between CS and Education graduates)

2. A course-specific permit for any teacher (certified in another area) who completes the professional development offered by a vendor that is approved by the State Department of Education (e.g., Code.org, PLTW); this allows a teacher who completes the endorsed PD to be certified to teach the course associated with the PD (but only that one specific course) 
3. A CS endorsement for any certified teacher who passes the ETS CS Praxis exam with a score that is set by the Alabama State Department of Education (e.g., a 149 on the ETS 5652 exam for CS [9])

4. A special career and technical education certificate that allows those with industry experience to become CS teachers.

We are discussing with our State Department of Education approval for our two-course pathway serving as a coursespecific permit for AP CSP (option 2 mentioned above). We base the justification for approving our course for the course-specific option on the comparative performance on the Praxis exam between our pre-service students and existing in-service teachers. In the following subsection, we elaborate on this point and discuss our recent success in preparing our most recent student cohort for the ETS Praxis 5652 exam (option 3 above).

\subsection{Summer Praxis Preparation Success}

During Summer 2019, we provided an online six-week summer preparatory training course for the ETS CS Praxis exam (offered in collaboration with WeTeach CS at the University of TexasAustin). Each participant completed the full course within 33 hours, on average. We offered the course to our pre-service cohort students (11 total pre-service teachers) and to several inservice teachers in our state (11 total in-service teachers) who previously completed an endorsed PD experience and have been teaching AP CSP for several years. Among the 22 course participants, 12 took the ETS 5652 Praxis exam in July and 4 others took the exam in Fall; not all course participants took the exam. Table 1 shows the participant numbers and results of the Praxis exam.

Table 1. Results of ETS CS Praxis Preparation Course

\begin{tabular}{|l|c|c|c|c|}
\hline & $\begin{array}{c}\text { Total Course } \\
\text { Participants }\end{array}$ & $\begin{array}{c}\text { Total } \\
\text { Exams }\end{array}$ & $\begin{array}{c}\text { Passed Cut } \\
\text { Score (149) }\end{array}$ & $\begin{array}{c}\text { Average } \\
\text { Score }\end{array}$ \\
\hline Pre-Service & 11 & 9 & 9 & 175 \\
\hline In-Service & 11 & 7 & 6 & 166 \\
\hline
\end{tabular}

Among those who took the Praxis exam, we can report the following results:

- All 9 of the pre-service students passed the exam and 6 of the 7 in-service teachers passed the exam. Those who passed can have their scores sent to our State Department of Education to be designated as CS certified educators (pre-service SEMA students will be certified officially when they graduate and establish primary certification in mathematics).

- On average, the pre-service students who completed our two-course pathway scored 9 points higher than in-service teachers who received PD in the past and had taught a CS course at least once.
- Two SEMA students received very high scores of 200 (perfect) and 195, and 3 other SEMA students received a score of 184 . We were remarkably surprised by the level of success of these students and look forward to obtaining additional data from future SEMA cohorts in our project.

\subsection{Pre-Service Praxis Preparation Feedback}

Among the pre-service students who participated in the Praxis preparation course and completed the exam, we asked for their response to a survey about their CS 104 and CS 492 experiences, in conjunction with the Praxis preparation summer course. Below are some observations from that survey:

- On average, students reported that they spent 33 hours on the Praxis preparation and every student completed all four modules. All students agreed that the six-week period was sufficient for completing the preparation.

- All of the students stated that the order of the twocourse sequence, followed by summer Praxis preparation was a key influence on their confidence in teaching CS in the future. One student responded, "The Praxis Prep course was designed specifically for the passing of the Praxis, the CS courses were geared towards learning CS and how to teach it."

- All of the students who responded expressed the importance of the CS 492 course as a prerequisite to the Praxis preparation. One student responded, "A lot of things like abstraction and global impact were already covered in 492 so the content for that in the prep course went super quick, and it was easy on the Praxis as well."

- All of the SEMA students agreed that summer was the perfect time for participating in the Praxis preparation as a complement to the previous two-course pathway.

\section{Lessons Learned and Key Observations}

Over the past two cohort implementations of our project, we have adapted our approach based on feedback from project participants. We summarize the lessons that we learned on our project, and comment on what we believe are key factors that suggest benefits of pre-service teacher preparation over current in-service PD models.

\subsection{Lessons Learned from Project Feedback}

With our Cohort 1 group (2017-2018), we provided many opportunities in the CS 492 course for student exposure to multiple AP CSP curricula providers. For SEMA students who had an interest in middle school, we also introduced them to Bootstrap Algebra [10]. The CS 492 course for the first cohort introduced (both in person, and by virtual webinars) students to many state and national CS educators who encouraged the students to understand the need for diversity and inclusion in order to meet the goals of CSforAll. The first cohort also met many existing AP CSP teachers who have been the pioneer 
leaders in our state, as well as key personnel at our State Department of Education who encouraged students in their preparation to be CS educators (our Governor's education policy lead attended a CS 492 course to encourage the SEMA students)..

During our interactions with Cohort 2 (2018-2019), we studied the feedback and evaluations collected from Cohort 1 and made changes to several aspects of CS 492: 1) we adjusted the pacing of the course to provide more time to complete and reflect on homework assignments, particularly during stressful times when students are preparing for their edTPA (Teacher Performance Assessment) subject-specific teacher assessments that are required for their program; 2) we adjusted the observation requirements when visiting local AP CSP classrooms to allow more meaningful participation with high school students in the classes that they were visiting; 3 ) the Cohort 2 Create Performance Task was better scaffolded to ease SEMA students into an improved understanding of the rubrics and exam grading process shared by the College Board, and 4) the summer Praxis preparation course was initiated through sample AP CSP and Praxis exam questions that were discussed in groups during CS 492 class periods.

The following are several take-aways that were key to our understanding of the project evolution:

1. Instilling Confidence in SEMA Student CS Content Knowledge: A key objective of the two courses is to build confidence in pre-service SEMA students and positively impact their perceptions of how effective they would be as CS educators. The two-course pathway provided opportunities to grow and learn within a student peer learning community that prompted exploration of teaching methods, as well as time for reflection and development of skillsets (e.g., programming prowess). A student expressed the following in response to a final course survey, "Being able to feel confident teaching two subjects made me very marketable when finding a job and also put me at ease when getting ready to teach. I have more teaching strategies to use with both subjects rather than just one."

2. Understanding the Culture of the K-12 CS Community: In addition to instilling confidence in our students, it was also important to build awareness of the current state of CS as situated within the momentum of state and national efforts. Because most of our SEMA students did not have access to a CS course at their own high school, they had very little knowledge of the opportunities in CS education before they began the pathway program. It was evident that we needed to recruit a cohort of students and expose them to CS education career paths and culture. Students read and discuss topics of diversity and inclusion, and hear from national advocates of CSforAll, to help them understand how CS can bring new opportunities to the communities that they will serve as future educators.
3. Connecting CS Concepts to Mathematics Interest: We perceived that it was advantageous to connect topics from the SEMA curriculum within a CS context to help intertwine objectives and lighten cognitive load (e.g., explaining how the factorization of prime numbers is important to public key cryptography methods and the overall global impact of secure commercial transactions, or how linear algebra can be used to animate the rotations of an object in a game that they are developing for their Create PT assignment).

\subsection{Comparison of Pre-/In-Service PD Models}

Although more empirical analysis is needed beyond our small evaluation in Section 4.1 (and results in Table 1), we believe that the initial comparative success between the pre-service SEMA students and existing in-service CS teachers on the ETS CS Praxis exam is an important observation that suggests our preservice CS preparation meets or exceeds the current PD approaches used for training in-service teachers in CS content knowledge.

The overall amount of time spent in training is the key difference between the pre-service and in-service PD approaches. The pre-service SEMA students experience extends across an entire year with 200-215 hours of engagement, while most in-service training is isolated to a week in summer and two weekends over the academic year (55-65 hours). The following are potential factors influencing the benefits of pre-service training over the current PD models used for in-service professional learning:

1. Contact Hours

a. Our pre-service students are enrolled in two classes that have a combined 96 hours of contact (each of the two courses is 16 weeks at 3 hours per week), in addition to opportunities to attend CS conferences and College Board AP Summer Institutes.

b. Most in-service CS PD occurs over a single week in summer (30-40 hours), and weekend followups in Fall and Spring (additional 25 hours).

2. Programming Practice and Content Reflection

a. SEMA students must complete five separate programming projects and five additional homework assignments over the 32 weeks of enrolled participation in both courses. We estimate that they spend an additional 40 hours to complete these assignments.

b. The intense nature of summer and weekend PD does not offer an opportunity for in-service teachers to develop their own programming skills. In-service PD offerings rarely, if ever, ask teachers to complete out-of-training programming exercises that are essential toward developing programming skills needed in teaching the Big Idea of Programming in AP CSP. 
3. Classroom Observation and Development Opportunities: Pre-service preparation provides opportunities to visit multiple classrooms of current AP CSP teachers during the academic year. Our approach affords extended time for SEMA students to develop lesson plans over an entire semester, to be presented and critiqued by classmates. SEMA students also present their lesson plans in the local classrooms where they are observing, with guidance from the host AP CSP teacher. The intense nature of current in-service PD models does not allow time for observation of more expert teachers in a natural classroom setting.

By spreading the pre-service training over an entire year with constant contact through diverse activities, we believe that there are many advantages to pre-service CS teacher preparation compared to current in-service PD models. This observation suggests that we need more collaboration between Colleges of Education and Computer Science Departments at institutions of higher education to prepare the pipeline of future K-12 CS educators.

\section{Conclusion}

The rising interest in K-12 CS in the USA has caused a challenge with respect to a shortage of educators who are prepared to introduce new CS courses in their schools. Much of the recent focus in addressing this challenge has been on the preparation of in-service teachers who are currently certified in another area, but may lack initial CS content knowledge. To address the challenges of scale associated with expanding CS coverage in more schools, Colleges of Education must begin to provide experiences for students who desire to teach CS at a future school. In this experience report, we shared our approach and initial results in developing a two-course pathway and complementary set of experiences for SEMA students who desire to teach CS in addition to mathematics. We have several ideas for expanding our efforts. Future work is planned for the following activities:

- Continue discussion with our Start Department of Education regarding the placement of our two-course pathway as an endorsed curriculum to satisfy the course-specific permit option mentioned in Section 4.

- Design a third course that is more programming centric. The existing CS 492 would become more of a traditional education pedagogy course, and the new programming course would cover Java to help familiarize pre-service students with AP CSA. Several students have expressed in open survey response questions that they felt the need for an additional technically focused course.

- Explore the option of converting our pathway courses to online delivery and open up the opportunity to students at Colleges of Education at other institutions in our state, with perhaps a specialization add-on for
CS education to any student who receives certification in some other area.

- Expand the focus to other pre-service students. Our concentration has been with SEMA students as a first effort, but we are also considering how science and other focus areas of teacher preparation could benefit from a similar pathway.

\section{ACKNOWLEDGMENTS}

Funding for this project was made possible by the National Science Foundation award \#1738849. Any opinions, findings, and conclusions or recommendations expressed in this material are those of the author(s) and do not necessarily reflect the views of the National Science Foundation.

\section{REFERENCES}

[1] Q. Fottrell (2019). Here's the No. 1 Highest Paid, Most In-demand Job in Every American State, Marketwatch, August 30, 2019. https://www.marketwatch.com/story/heres-the-no-1-highest-paid-and-fastestgrowing-job-in-every-us-state-2019-08-20

[2] J. Cuny, D. Baxter, D. Garcia, J. Gray, and R. Morelli (2014), CS Principles Professional Development: Only 9, 500 to Go! ACM Technical Symposium on Computer Science Education (SIGCSE), Atlanta, GA, March 2014, pp. 543-544.

[3] L. Delyser, J. Goode, M. Guzdial, Y. Kafai, and A. Yadav (2018). Priming the Computer Science Teacher Pump: Integrating Computer Science Education into Schools of Education. computingteacher.org. Available at: https://drive.google.com/file/d/1DXgpLjl_k87TVpQ0cLusfdjnYySIgIjT/view

[4] M. Pérez, and P. Romero (2014). Secondary STEM teacher preparation as a top priority for the university of the future. The fournal of the World Universities Forum, 6(4), pp. 21-36.

[5] A. Yadav, C. Stephenson, and H. Hong (2017). Computational Thinking for Teacher Education. Communications of the ACM, 60(4), pp. 55-62.

[6] Code.org (2019) Code.org Advocacy Coalition, https://advocacy.code.org/

[7] Expanding Computing Education Pathways (2019), https://ecepalliance.org/

[8] Code.org. (2019).Nine Policy Ideas to Make Computer Science Fundamental to K-12 Education. https://code.org/files/Making_CS_Fundamental.pdf

[9] Education Testing Service (ETS) Computer Science Praxis Exam 5652, https://www.ets.org/praxis/prepare/materials/5652

[10] E. Schanzer, K. Fisler, and S. Krishnamurthi (2018). Assessing Bootstrap: Algebra Students on Scaffolded and Unscaffolded Word Problems, ACM Technical Symposium on Computer Science Education (SIGCSE), Baltimore, MD, March 2018, pp. 543-544.

[11] R. Odom-Bartel, J. Gray, and J. Zelkowski (2020). Preparing Secondary Education Mathematics Pre-service Teachers for AP Computer Science Principles: A Two-Course Design Model, in Preparing Teachers to Teach Computer Science: Models, Practices and Policies (Chrystalla Mouza, Aman Yadav, and Anne Leftwich, editors), Information Age Publishing, 2020.

[12] H. Abelson, K. Ledeen, and H. Lewis (2008). Blown to Bits: Your Life, Liberty, and Happiness After the Digital Explosion, Addison-Wesley, available at: http://www.bitsbook.com/ 